\title{
Harmonic Mitigation Using Passive Harmonic Filters: Case Study in a Steel Mill Power System
}

\author{
Byungju Park ${ }^{1}$, Jaehyeong Lee ${ }^{2}\left(\mathbb{D}\right.$, Hangkyu Yoo $^{1}$ and Gilsoo Jang ${ }^{2, *(D)}$ \\ 1 PQ Tech Incorporation, Suwon 16690, Korea; bjpark@pqtech.co.kr (B.P.); hkyoo@pqtech.co.kr (H.Y.) \\ 2 School of Electrical Engineering, Korea University, Seoul 02841, Korea; bluesky6774@korea.ac.kr \\ * Correspondence: gjang@korea.ac.kr; Tel.: +82-2-3290-3246
}

Citation: Park, B.; Lee, J.; Yoo, H.; Jang, G. Harmonic Mitigation Using Passive Harmonic Filters: Case Study in a Steel Mill Power System. Energies 2021, 14, 2278. https://doi.org/ $10.3390 /$ en 14082278

Academic Editor: Gabriel

Nicolae Popa

Received: 18 March 2021

Accepted: 15 April 2021

Published: 18 April 2021

Publisher's Note: MDPI stays neutral with regard to jurisdictional claims in published maps and institutional affiliations.

Copyright: (c) 2021 by the authors. Licensee MDPI, Basel, Switzerland. This article is an open access article distributed under the terms and conditions of the Creative Commons Attribution (CC BY) license (https:// creativecommons.org/licenses/by/ $4.0 /)$.

\begin{abstract}
In this study, we mitigated the harmonic voltage in a power system that contained the roughing mill (RM) and finishing mill (FM) motor drives. AC/DC converter type RM drive is a non-linear, large-capacity varying load that adversely affects power quality, e.g., a flicker, voltage distortion, etc. The voltage drop can be compensated within a certain limit by using the proper capacity of a power capacitor bank. In addition, the voltage distortion can be controlled as per the guidelines of IEEE Std. 519 using the passive harmonic filter corresponding to the characteristic harmonics of the motor drive load. The passive harmonic filter can provide an economical solution by mitigating the harmonic distortion with a proper reactive power supply. However, at the planning level, attention should be paid to avoid system overvoltage that is caused by the leading power under light load conditions and also the problem of parallel resonance between the harmonic filter and the step-down transformer. In addition, when designing the filter reactor, the K-factor and peak voltage must be considered; the filter capacitor also requires a dielectric material that considers the harmonic peak voltage. The purpose of this study was to acquire a better understanding of the filter applications as well as verify the field measurement, analysis, and design of harmonic filters together with its performance.
\end{abstract}

Keywords: converter; easy power system software; harmonic distortion; hi-pass filter; IEEE Std. 519; passive harmonic filter; single tune filter

\section{Introduction}

The plate, in this paper, refers to an iron plate that is made by rolling an intermediate slab obtained through the iron-manufacturing process or the steel-manufacturing process. It is usually a steel plate with a thickness of at least $6 \mathrm{~mm}$ that is difficult to process and is generally used in the manufacturing of ships, bridges, boiler pressure vessels, etc. Owing to the characteristics of speed and torque control, a Ward Leonard, mercury arc, and thyristor converter have been used in the past. In recent years, this development process has been extended to the cyclo-converter, rectifier-pulse width modulation (PWM) inverter, and active rectifier-PWM inverter [1].

The rolling mill for plate processing is operated in the acceleration speed, pass, and idling modes. To satisfy these characteristics, precise control performance of constant torque and braking characteristics are required in response to a wide speed control range and whirlwind overload. Generally, the voltage drop and the voltage distortion of the mill motor drive converter system reduce the output torque of the motor drive and adversely affect the control performance. Therefore, proper reactive power compensation and harmonic mitigation of the mill motor drive system can reduce the system losses and increase the productivity and quality of the plate [1,2]. Figure 1 shows the power fluctuation of the mill motor drive system. The measured apparent $(S)$, active $(P)$, and reactive powers $(\mathrm{Q})$ of the plate mill system are red, green, and blue, respectively. 


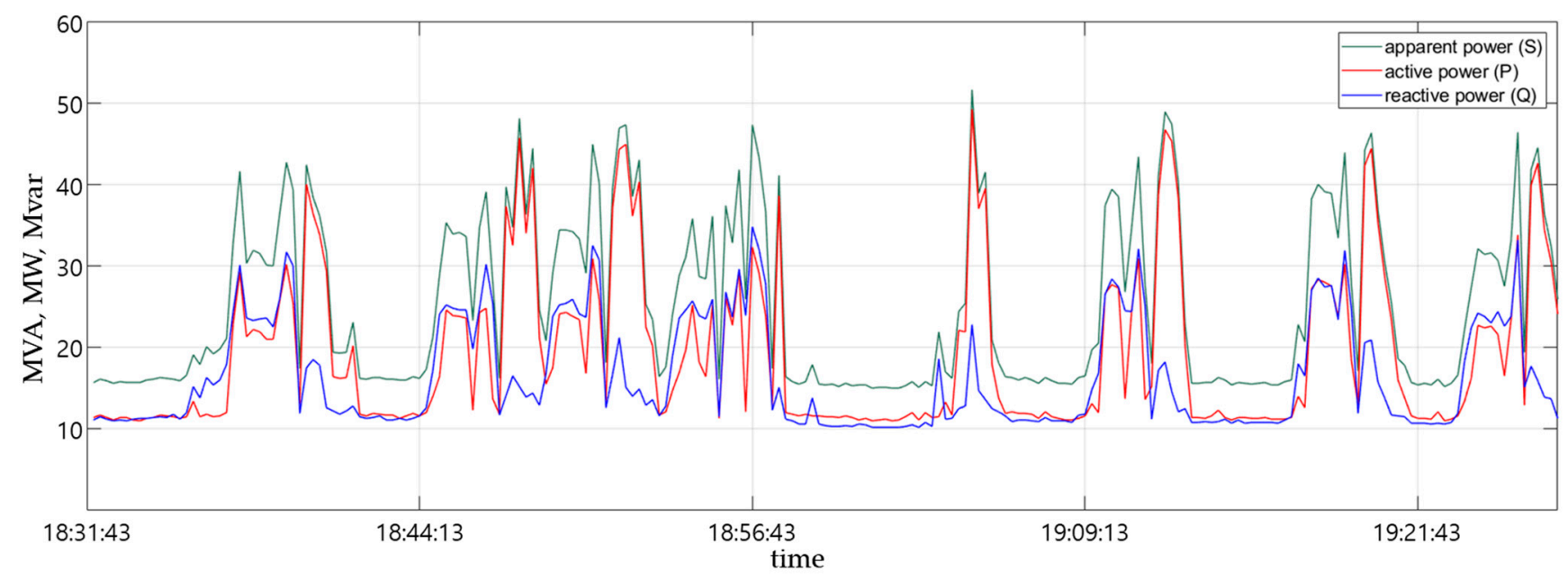

Figure 1. Measured P, S, and Q on plate mill system.

Harmonics generated in the power system have various adverse effects. First, the effects of harmonics on electrical equipment are generally as follows: disturbance, increased losses, extra neutral current, improper working of metering devices, resonance problems [3,4]. In addition, the effects of harmonics on the power system are as follows: the possibility of amplification of harmonic levels, efficiency reduction, ageing of electrical plant components, and malfunction [4,5]. To solve these problems, various studies have been conducted to mitigate harmonics of distribution systems using filters [6-11]. In particular, the effect is evaluated by sharing application case study on the real power system as in this paper [12-15].

Harmonic distortion can be suppressed using two methods: a passive power and an active power filter. A passive filter is the conventional solution to reduce harmonic distortion [16-18]. While it is simple, a passive filter does not always respond correctly to dynamics behavior [19]. This type of filter has been continuously developed over the past years, and notch filter (which bypasses a specific harmonic current) and high pass filter (which allow a large percentage of all harmonics above the corner frequency to pass through) are typical $[17,18]$. With the development of power electronics (PE) technology, active power filter has been used to mitigate harmonics. The basic principle is to use PE to create a specific current component that cancels the harmonic current component. Active power filter is better than passive filter in terms of technical aspects such as resonance, the range of harmonic mitigation range, and occupied bulky space, but has a disadvantage of being expensive [20].

In this paper, system modeling, harmonic calculation, filter design, construction, and field measurement were performed for the steel mill power system, and the results were evaluated based on IEEE Std. 519 [21]. Conventionally, to minimize voltage fluctuation, SVC (static var compensator) combined with TCR (thyristor-controlled reactor) and passive tuned filter, or STATCOM combined with PWM inverter module and high-pass filter is used [2,22]. However, depending on the system conditions, a passive filter can be a sufficient solution. In this case, the space required for the TCR can be saved and the power loss on TCR can be reduced [1].

\subsection{Brief Description of the Plate Mill System \\ 1.1.1. Simplified Single Line Drawing}

The outline view of the plate mill system is shown in Figure 2. As seen from Figure 2, the short-circuit capacity (SCC) of the system at the grid side is $2500 \mathrm{MVA}, \mathrm{X} / \mathrm{R} 10$. On the left portion of Figure 2, the main system loads, roughing mill (RM) TOP, and BOT are in the form of a 5.5 MW DC motor drive with a 12-pulse thyristor rectifier. The finishing mill (FM) TOP and BOT are in the form of an $8.8 \mathrm{MW}$ synchronous motor with an injection enhanced gate transistor (IEGT)-PWM inverter. (TOP and BOT mean motors and inverters 
located at the upper and lower side of RM and FM, respectively.) There are three $22 / 3.3 \mathrm{kV}$, 3 phase, $20 \mathrm{MVA}$, step-down transformers in the middle that are used for the $3.3 \mathrm{kV}$ mill line, $3.3 \mathrm{kV} 2$ pre-leveler roll (PLR) power, and $3.3 \mathrm{kV}$ shear/finishing line.

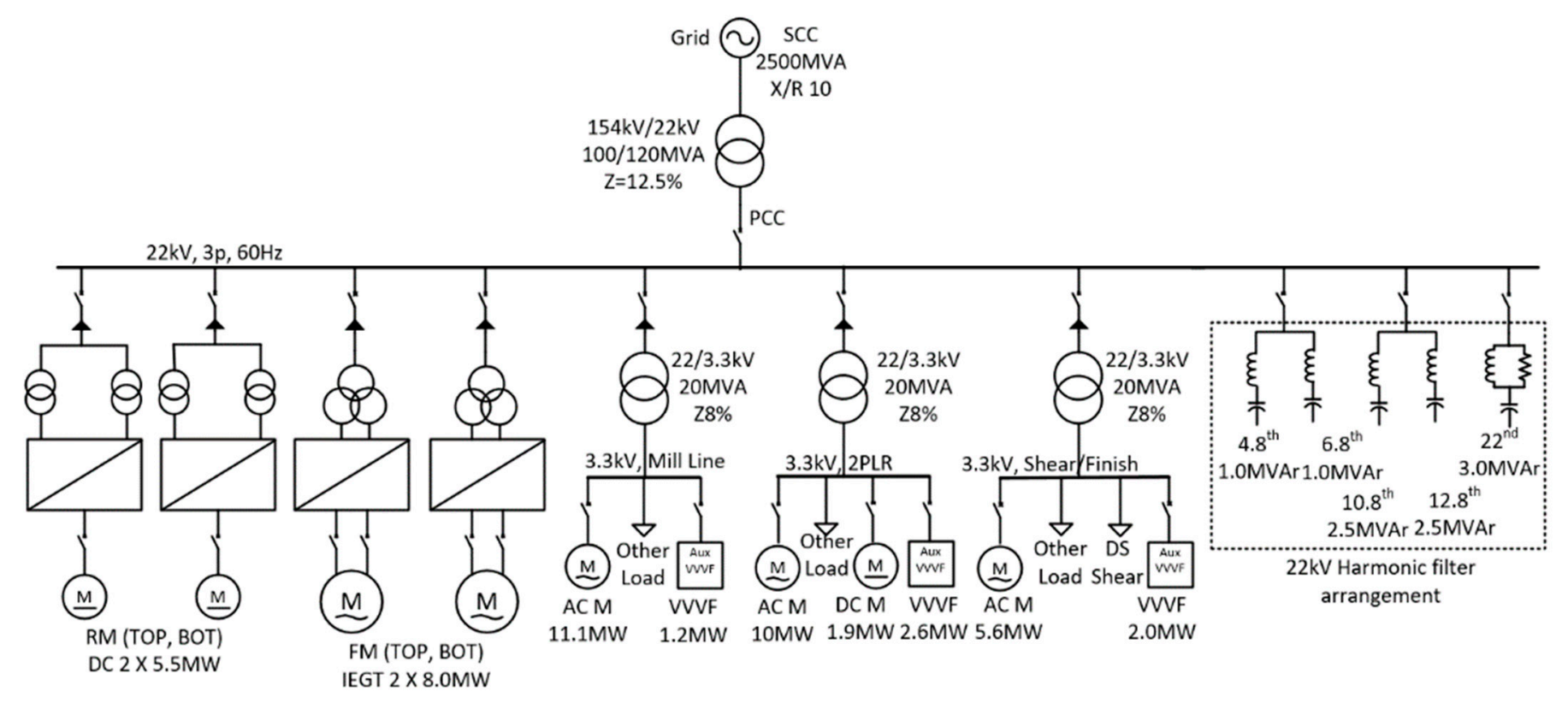

Figure 2. Simplified plate mill system single line drawing.

\subsubsection{Summation of Input Data}

As listed in Table 1, the SCC of the power supply utility is 2500 MVA, X/R 10, and specifications of the step-down transformers are $154 / 22.9 \mathrm{kV}, 100 \mathrm{MVA}$, and $\mathrm{Z}=12.5 \%$. For RM TOP and BOT, $167 \%$ of the rating was applied considering the overload characteristics and $107 \%$ for FM TOP and BOT. In the $3.3 \mathrm{kV}$ mill line, 2PLR, and finishing line, the AC motor, FM field, variable voltage variable frequency of the thyristor rectification and other loads were included.

Table 1. Summation of major input data.

\begin{tabular}{cc}
\hline Clarification & Description \\
\hline Utility & $25,000 \mathrm{MVA}, \mathrm{X} / \mathrm{R} 10$ \\
Step down trans. & $154 \mathrm{kV} / 22 \mathrm{kV}, 100 \mathrm{MVA}, \mathrm{Z}=12.5 \%$ \\
RM TOP & $9.167 \mathrm{MW},-9.352 \mathrm{MVAR}(167 \%$ of rating), DC motor \\
RM BOT & $9.167 \mathrm{MW},-9.352 \mathrm{MVAR}(167 \%$ of rating), DC motor \\
FM TOP & $8.521 \mathrm{MW}, 0.852 \mathrm{MVAR}(107 \%$ of rating), synchronous motor \\
FM BOT & $8.521 \mathrm{MW},-0.852 \mathrm{MVAR}(107 \%$ of rating), synchronous motor \\
Step down trans. & $22 \mathrm{kV} / 3.3 \mathrm{kV}, 20 \mathrm{MVA}, \mathrm{Z}=8 \%, 3$ set \\
Mill line $3.3 \mathrm{kV}$ & $16.4 \mathrm{MW},-11.1 \mathrm{MVAR}$ \\
& (AC motor, FM field, VVVF, and others) \\
2PLR 3.3 kV & $19.1 \mathrm{MW},-12.8 \mathrm{MVAR}$ \\
& (AC motor, DC motor, VVVF, and others) \\
Shear / finishing $3.3 \mathrm{kV}$ & $17.8 \mathrm{MW},-11.6 \mathrm{MVAR}$ \\
& (AC motor, shear, VVVF, and others)
\end{tabular}

Tables 2 and 3 list the harmonic current spectrum of the RM TOP/BOT and FM TOP/BOT mill motor drives. RM TOP/BOT represents the typical characteristic harmonic current of the 12-pulse thyristor rectifier, and as listed in Table 1, the reactive power injection is also large. On the other hand, FM TOP/BOT is a PWM inverter drive with a large capacity IEGT, and the harmonic current and reactive power injection are low. 
Table 2. Harmonic injection on RM and FM drives.

\begin{tabular}{ccccc}
\hline \multicolumn{5}{c}{ Harmonic Current $\boldsymbol{I}_{\boldsymbol{h}}(\mathbf{A}) \mathbf{2} \mathbf{2 2} \mathbf{~ k V}$ Bus Base } \\
\hline h Order & RM TOP & RM BOT & FM TOP & FM BOT \\
\hline 5 & 0 & 0 & 1.81 & 1.81 \\
7 & 0 & 0 & 0.31 & 0.31 \\
11 & 16.66 & 16.66 & 4.6 & 4.6 \\
13 & 14.1 & 14.1 & 3.53 & 3.53 \\
17 & 0 & 0 & 0.4 & 0.4 \\
19 & 0 & 0 & 1.25 & 1.25 \\
23 & 6.97 & 6.97 & 1.25 & 1.25 \\
25 & 6.42 & 6.42 & 0.65 & 0.65 \\
29 & 0 & 0 & 0.21 & 0.21 \\
31 & 0 & 0 & 0.14 & 0.14 \\
35 & 3.93 & 3.93 & 0.49 & 0.49 \\
37 & 3.72 & 0.72 & 0.65 & 0.65 \\
41 & 0 & 0 & 0.07 & 0.07 \\
43 & 0 & 1.95 & 0.13 & 0.13 \\
47 & 1.95 & 1.87 & 0.44 & 0.44 \\
49 & 1.87 & & 0.64 & 0.64 \\
\hline
\end{tabular}

Table 3. Harmonic injection on $3.3 \mathrm{kV}$ buses.

\begin{tabular}{cccc}
\hline \multicolumn{4}{c}{ Harmonic Current $\boldsymbol{I}_{\boldsymbol{h}}(\mathbf{A}), \mathbf{2 2} \mathbf{~ k V}$ Bus Base } \\
\hline h Order & Mill Line & 2PLR & Shear Finishing \\
\hline 5 & 40.7 & 152.7 & 149.4 \\
7 & 28.1 & 105.5 & 103.2 \\
11 & 20 & 74.8 & 73.2 \\
13 & 12.8 & 48 & 47 \\
17 & 10.5 & 38.4 & 38.5 \\
19 & 6.7 & 25.2 & 24.6 \\
23 & 4.2 & 15.7 & 15.4 \\
25 & 3.2 & 11.8 & 11.3 \\
\hline
\end{tabular}

\section{Harmonic Filter Design}

There are various effects of harmonics, such as overheating, electromagnetic noise of wires, noise of transformers, and malfunction of power devices. In addition, it increases the system losses and causes reliability problems [21,23,24]. A harmonic filter (HF) is a device used to reduce the harmonic current or harmonic voltage of the system to protect the power equipment from these problems $[25,26]$. HFs usually comprise capacitors, inductors, and resistors to provide a lower impedance than the system impedance at one or more specific frequencies as per requirement [23]. Thus, the filter can be used to lower the impedance of the corresponding order, absorb the harmonic current of the order, and reduce the harmonic voltage. In general, the filter tuning is set slightly lower than the corresponding order, which allows only a positive error when determining the manufacturing error of the filter capacitor and reactor [26,27]. Due to manufacturing error, if the tuning is at a higher frequency than that of the corresponding order, the harmonic current of the order acts in the leading phase, thereby increasing the harmonic voltage.

\subsection{Capacitor Banks}

The capacitor bank of the high-voltage system is mainly in the form of a wye connection, and it is a double wye type when the capacity is large. The neutral is classified as grounded and ungrounded. In the case of a grounded neutral, the recovery voltage can be significantly reduced [28]. On the other hand, there is a disadvantage that the current flows to the ground, which can cause communication failure and ground relay malfunction. In this study, an unground double wye connection was adopted that was easy to configure for 
open delta unbalance voltage sensing protection in a $22 \mathrm{kV}$ system. For the capacitor, the voltage rating should be determined by considering the harmonic voltage synthesis due to the inflow of harmonic current (for reference, the $V_{S U M}$ of the 5th harmonic filter capacitor was considered as $1.26 \mathrm{pu}$ ) and hazed polypropylene film and phenyl xylyl ethane (PXE) oil, which have excellent performance, were used [27].

$$
V_{S U M}=V_{1 p u-s y s}+\sum_{h \neq 1}^{h} V_{h p u-s y s}(\mathrm{pu})
$$

where $V_{S U M}$ is the summation of the capacitor voltage in $\mathrm{pu}, V_{1 p u-s y s}$ is the system fundamental voltage of the capacitor expressed in $\mathrm{pu}, V_{h p u-s y s}$ is the system harmonic voltage of the capacitor expressed in pu, and $h$ is the harmonic order.

\subsection{Series Reactors}

In the design of a series reactor (SR), the derating factor (DF) should be applied considering the loss caused by the inflow of harmonic current. The DF is related to the $K$-factor $[23,29]$ and the harmonic loss factors $\left(F_{H L}\right)[30]$.

\subsubsection{DF Using K-Factor}

In the case of SR of 5th harmonic filter, the loss was $11.6 \mathrm{~kW}$ (the fundamental current loss was $2.7 \mathrm{~kW}$ ), K-factor was 38, and DF was 0.26 pu (eddy current loss was 0.08 ). Compared to the case where only the fundamental current flows, this case should consider the loss and current tolerance of 3.5 to 4.0 times.

$$
\begin{gathered}
D F=\frac{\left(1+P_{E C-R}\right)}{\left(1+P_{E C-R} \times K_{\text {factor }}\right)}(\mathrm{pu}) \\
K_{\text {factor }}=\frac{\sum_{h=1}^{h}\left(I_{h}\right)^{2}(h)^{2}}{I_{\text {Rating }}^{2}}
\end{gathered}
$$

where $D F$ is expressed as a per unit, $P_{E C-R}$ is the eddy current loss factor $(8-12 \%), K_{\text {factor }}$ is a weighting of the harmonic currents, $I_{h}$ is the harmonic current of h order into the SR, and $I_{\text {Rating }}$ is the rating current of SR.

\subsubsection{DF Using $F_{H L}$}

In addition, the derating can be calculated by applying the $F_{H L}$ instead of $K$-factor. In this case, $F_{H L}$ was 15.91. The DF to which $F_{H L}$ was applied in $P_{L L-R}(0.563 \mathrm{pu})$ and $P_{E C-R}(0.08 \mathrm{pu})$ was $0.497 \mathrm{pu}$. Compared to the former method, it shows about twice the difference [31].

$$
\begin{gathered}
F_{H L}=\frac{P_{E C-R}}{P_{E C-O}}=\frac{\sum_{h=1}^{h}\left(\frac{I_{h}}{I_{1}}\right)^{2}(h)^{2}}{\sum_{h=1}^{h}\left(\frac{I_{h}}{I_{1}}\right)^{2}} \\
D F=\frac{\left(P_{L L-R}\right)}{\left(1+P_{E C-R} \times F_{H L}\right)}(\mathrm{pu}) \\
P_{L L-R}=I_{R}^{2} R_{D C}+F_{H L} P_{E C-R}+F_{H L-S T R} P_{O S L-R}
\end{gathered}
$$

where $P_{L L-R}$ is the loss of the load, $P_{E C-O}$ is the measure eddy current loss of winding under current and frequency conditions, $R_{D C}$ is the DC resistance, $F_{H L-S T R}$ is the harmonic loss factor of other stray losses of transformer winding, and $P_{O S L-R}$ is the rated other stray loss. 
The harmonic filter reactor loss can be calculated by the coil, core, and gap losses. (7) shows the calculation formula for the total coil loss.

$$
P_{C}=\sum\left[I(h)^{2} R_{a c}(h)+P_{\text {eddy }}(h)+P_{\text {stray }}(h)\right.
$$

where $P_{C}$ is the total coil loss $(\mathrm{W}), I(h)$ is the $h$ th harmonic current (Arms), $R_{a c}(h)$ is the conductor resistance at $h$ th $(\Omega), P_{\text {eddy }}(h)$ is the $h$ th eddy current loss $(\mathrm{W})$, and $P_{\text {stray }}(h)$ is the $h$ th stray loss $(\mathrm{W})$.

The core loss and gap loss are strongly influenced by the harmonic order and magnitude. The core and gap losses should be designed to be less than $40 \%$ and $20 \%$ of the total coil loss, respectively. In this case, the core and gap losses are $27 \%$ and $1.05 \%$ of the total losses, respectively. Moreover, in the design process, several parameters must be considered. Among them, since the voltage at the point where the filter is connected is low, saturation was not considered. In addition, inductance is determined by the cross-sectional area of the core and the width of the air gap [27].

There are two types of cores: the iron and air core. The iron core is efficient in terms of the installation space but has disadvantages such as magnetic saturation due to core hysteresis characteristics, noise between core layers, and partial heat generation in steel structures. The air core has a good stability because of its excellent linearity and low noise, but it has disadvantages that it requires a large installation space to maintain a distance considering the effect of the magnetic field and is vulnerable to external pollutants. In this study, an SR with an oil-filled magnetic shield air core type was selected, which took advantage of both these types due to the limited installation space.

\subsection{Harmonic Filter System}

The RM TOP/BOT and FM TOP/BOT rolling mill drives were connected to the secondary bus of a $154 / 22 \mathrm{kV}, 100$ MVA transformer. From this bus, power was supplied to the auxiliary devices such as a mill line, 2PLR, and shear/finishing line load via three transformers $(22 / 3.3 \mathrm{kV}, 20 \mathrm{MVA})$. The filter banks were connected based on this main bus, and the harmonic filter was designed to perform harmonic filtering and reactive power compensation [32]. The total reactive power compensation capacity of the filter was 10 MVAR and consisted of a total of 5 filter banks, including 4 single-tuned filters and 1 high-pass filter.

The reactive power compensation capacity $Q_{C}$, capacitance $C$, SR inductance $L$, and quality factor $Q_{f}$ can be calculated, respectively, as illustrated in (8)-(12) [27,32].

$$
\begin{gathered}
C=\frac{1}{\omega} \frac{Q_{C}}{V_{L}^{2}}\left(1-\frac{1}{h^{2}}\right) \\
L=\frac{1}{\omega} \frac{V_{L}^{2}}{Q_{C}} \frac{h}{h^{2}-1} \\
R_{d}=\gamma \frac{V_{L}^{2}}{Q_{C}} \frac{h}{h^{2}-1} \\
\gamma=\frac{R_{d}}{\omega L h}=\frac{R_{d}}{Z_{0}} \\
Q_{f}=\frac{\omega L h}{R_{s}}=\frac{Z_{0}}{R_{d}}
\end{gathered}
$$

where $Q_{C}$ is the compensation capacity of the fundamental frequency, $V_{L}$ is the system line voltage, $C$ is the capacitance of the filter bank, $L$ is the inductance of the filter bank, $R_{d}$ is the damping resistor of the high-pass filter, $Z_{0}$ is the characteristic impedance, $\gamma$ is the quality factor of the high-pass filter, $R_{S}$ is the resistance of the $\mathrm{SR}$, and $Q_{f}$ is the quality factor of the band-pass filter. Table 4 illustrates the electrical design parameters of the 5 th, 7th, 11th, 13th, and 22nd HF. 
Table 4. Harmonic filter design parameters.

\begin{tabular}{|c|c|c|c|c|c|c|}
\hline Description & Unit & $\begin{array}{l}\text { 4.8th HF } \\
\text { Band Pass }\end{array}$ & $\begin{array}{c}\text { 6.8th HF } \\
\text { Band Pass }\end{array}$ & $\begin{array}{l}\text { 10.8th HF } \\
\text { Band Pass }\end{array}$ & $\begin{array}{l}\text { 12.8th HF } \\
\text { Band Pass }\end{array}$ & $\begin{array}{l}\text { 22nd } \\
\text { Hi-Pass }\end{array}$ \\
\hline System VLL & $\mathrm{kV}$ & 22 & 22 & 22 & 22 & 22 \\
\hline Bank capacity & kVAr & 1000 & 1000 & 2500 & 2500 & 3000 \\
\hline Dimensional capacity & kVAr & 1046 & 1022 & 2522 & 2516 & 3006 \\
\hline Bank capacitance & $\mu \mathrm{F}$ & 5.24 & 5.36 & 13.58 & 13.62 & 16.41 \\
\hline Capacitor string voltage & $\mathrm{kV}$ & 23.01 & 22.49 & 22.19 & 22.14 & 22.05 \\
\hline Bank current & A1 & 26.24 & 26.24 & 65.61 & 65.61 & 78.73 \\
\hline $\mathrm{SR} \%$ reactance & $\%$ & 4.38 & 2.18 & 0.87 & 0.62 & 0.21 \\
\hline SR inductance & $\mathrm{mH}$ & 58.86 & 28.67 & 4.49 & 3.19 & 0.89 \\
\hline SR reactance & $\Omega$ & 22.19 & 10.81 & 1.69 & 1.2 & 0.34 \\
\hline SR ohmic resistance & $\Omega$ & 1.31 & 0.91 & 0.22 & 0.19 & 0.03 \\
\hline $\mathrm{SR} X / \mathrm{R}$ ratio & - & 16.9 & 11.9 & 7.5 & 6.3 & 10.1 \\
\hline Quality factor Q & - & 80.9 & 80.8 & 80.9 & 80.6 & 5 \\
\hline Damping $\mathrm{R}$ & $\Omega$ & - & - & - & - & 37 \\
\hline Reactor voltage & V1 & 582.3 & 283.6 & 110.9 & 78.8 & 26.6 \\
\hline
\end{tabular}

\subsection{Distribution Network Topology and Current Divider $H_{i d}(s)$}

The step-down transformer, main mill motor load, and harmonic filter banks can be expressed as shown in Figure 3, where $H_{i d}(s)$ is the current divider transfer function between the power system, and $I_{h}(s)$ is the harmonic current injected from the load. $I_{h}(s)$ is calculated as in (13) [33].

$$
H_{i d}(s)=\frac{I_{h s}(s)}{I_{h}(s)}=\frac{Z_{0}}{R_{d}}
$$

Figure 4 shows the attenuation of the filtering system as a function of the impedance of the power system. The filtering effect was insufficient with $h_{5}=-1.63 \mathrm{~dB}$. If the 5 th harmonic had a large proportion, better results could be obtained by moving the tuning order to $\mathrm{h}=4.9$ or increasing the capacity. The 11th, 13th, 23rd, and 25th order harmonics, which were of primary concern, demonstrated smooth filtering performance. The transfer function $\left(H_{i d}(s)\right)$ was obtained from an equivalent circuit substituted with a single phase based on the systematic equilibrium.

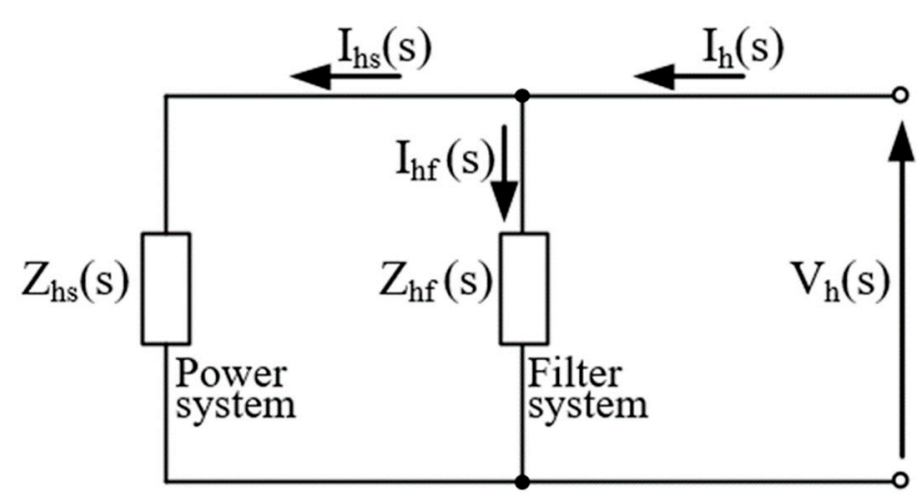

Figure 3. Conceptual $H_{i d}(s)$ divider. 


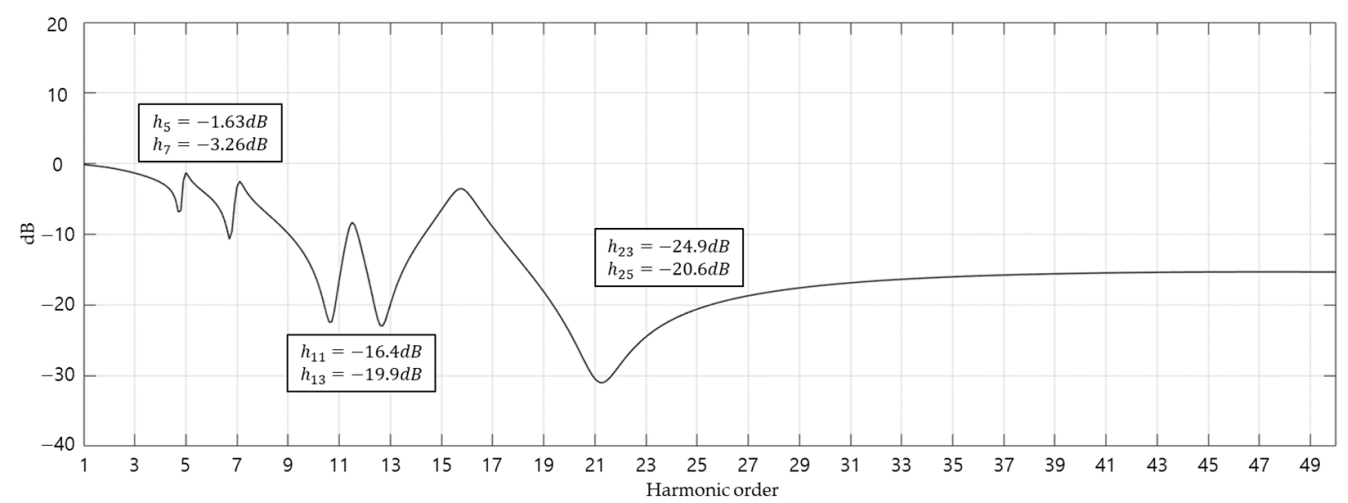

Figure 4. Frequency response of $H_{i d}(s)$.

\section{Easy Power System Software (ESA) Calculation Results}

3.1. Without Filters

Prior to harmonic current and voltage distortion calculation, the harmonic phase angle was assumed to be zero. Depending on the phase angle, the calculation result is drastically changed [6], and in this paper, the worst conditions were considered.

Table 5 lists the calculation results of the ESA assuming that there are no filters and shows the load flow, voltage distortion, and power factor. From the table it is seen that the voltage drops for $3.3 \mathrm{kV}$ mill line, $2 \mathrm{PLR}$, shear, and finishing line are $5 \%$, the voltage distortion $V_{\text {thd }}$ also exceeds both the KEPCO limits $(154 \mathrm{kV} \mathrm{1.5 \% ,} 22 \mathrm{kV} \mathrm{3 \%})$ and IEEE std. 519 (PCC $22 \mathrm{kV} \mathrm{5 \% ).} \mathrm{Tables} 6$ and 7 list the current report and voltage report of the IEEE Std. 519 [23]. From Table 6 it is seen that the harmonic current for Harmonic Number 11-16 is $5.21 \%$, exceeding the limit of $4.5 \%$, and for Harmonic Number $23-34$ is $1.72 \%$, exceeding the limit of $1.5 \%$. From Table 7 it is seen that the voltage distortion $V_{\text {thd }}$ is $9.27 \%$, exceeding the limit of $5 \%$, and the expected maximum individual voltage distortion exceeds the limit of $3 \%$ and is listed as $4.72 \%$. As shown in the simulation results to determine the planning level, installation of the harmonic filter is indispensable to mitigate the harmonic distortion and voltage compensation.

\subsection{With Filters}

Table 8 lists the results of the load flow, voltage distortion $V_{t h d}$, and power factor, assuming that the designed harmonic filter banks are connected to the $22 \mathrm{kV}$ bus. The load (S) on the $154 \mathrm{kV}$ bus was reduced from 47.65 to $42.6 \mathrm{MVA}$, and the voltage phase and voltage drop were improved on both the 22 and $3.3 \mathrm{kV}$ buses. The voltage distortion $V_{\text {thd }}$ was improved from 2.24 to $0.68 \%$ based on the $154 \mathrm{kV}$ bus, satisfying the KEPCO limit of $1.5 \%$ and also the power factor was improved from 0.82 to 0.91 . Tables 9 and 10 list the current distortion and voltage distortion at the $22 \mathrm{kV}$ bus, the current distortion was improved from $8.75 \%$ to $4.75 \%$, and the $V_{\text {thd }}$ improved from 9.267 to $2.819 \%$, satisfying both the KEPCO limit and the IEEE Std. 519 guideline.

Table 5. ESA calculation results for load flow, $V_{t h d}$, and power factors without filter.

\begin{tabular}{ccccccc}
\hline Bus & $\begin{array}{c}\text { Nominal } \\
\text { Voltage } \mathbf{( k V )}\end{array}$ & $\begin{array}{c}\text { Voltage } \\
\mathbf{( p u )}\end{array}$ & $\begin{array}{c}\text { Angle } \\
\mathbf{( d e g )}\end{array}$ & $\boldsymbol{V}_{\text {thd }} \mathbf{( \% )}$ & pf & S (MVA) \\
\hline 154 kV & 154 & 1.0 & 0.0 & $2.24^{*}$ & 0.82 & 47.65 \\
22 kV main & 22 & 0.97 & -2.8 & $9.27^{*}$ & 0.84 & 46.01 \\
RM TOP, BOT & 22 & 0.96 & -2.9 & $9.36^{*}$ & 0.70 & 15.72 \\
FM TOP, BOT & 22 & 0.96 & -2.9 & $9.36^{*}$ & 0.99 & 10.28 \\
ML 3.3 kV & 3.3 & $0.95^{*}$ & -4.2 & $10.23^{*}$ & 0.82 & 6.65 \\
2PLR 3.3 kV & 3.3 & $0.95^{*}$ & -4.4 & $12.75^{*}$ & 0.82 & 7.74 \\
S/F 3.3 kV & 3.3 & $0.95^{*}$ & -4.3 & $12.68^{*}$ & 0.82 & 7.14 \\
\hline
\end{tabular}

* violation of standards. 
Table 6. ESA calculation results for IEEE Std. 519 current report without filter-1.

\begin{tabular}{ccccccc}
\hline \multicolumn{7}{c}{ Harmonic Current Distortion in Percent of Plant Loading } \\
\hline $\begin{array}{c}\text { Harmonic } \\
\text { Number }\end{array}$ & $\mathbf{3 - 1 0}$ & $\mathbf{1 1 - 1 6}$ & $\mathbf{1 7 - 2 2}$ & $\mathbf{2 3 - 3 4}$ & $\mathbf{3 5 - 5 0}$ & ITDD (\%) \\
\hline Odd Harmonics & 4.2 & $5.21 *$ & 1.08 & $1.72 *$ & $0.74 *$ & 8.75 \\
IEEE Limits & 10 & 4.5 & 4 & 1.5 & 0.7 & 12.00 \\
Even Harmonics & 0 & 0 & 0 & 0 & 0 & 0.00 \\
IEEE Limits & 2.5 & 1.13 & 1 & 0.38 & 0.17 & 3.00 \\
Plant Load & & & & & & \\
kVA = 50,000 & & & & & & \\
PCC & & & & &
\end{tabular}

Table 7. ESA calculation results for IEEE Std. 519 current report without filter-2.

\begin{tabular}{ccc}
\hline \multicolumn{3}{c}{ Harmonic Voltage Distortion in Percent of PCC Base Voltage } \\
\hline & Max Individual & $V_{\text {thd }}(\mathbf{\%})$ \\
\hline PCC Bus & $4.720 *$ & $9.267^{*}$ \\
IEEE Limits & 3 & 5.00 \\
PCC Base kV $=22.000$ & & \\
\hline *violation of standards.
\end{tabular}

Table 8. ESA calculation results for load flow, $V_{\text {thd }}$, and power factors with filter.

\begin{tabular}{ccccccc}
\hline Bus & $\begin{array}{c}\text { Nominal } \\
\text { Voltage } \mathbf{( k V )}\end{array}$ & $\begin{array}{c}\text { Voltage } \\
\mathbf{( p u )}\end{array}$ & $\begin{array}{c}\text { Angle } \\
\mathbf{( d e g )}\end{array}$ & $\boldsymbol{V}_{\text {thd }} \mathbf{( \% )}$ & pf & S (MVA) \\
\hline 154 kV & 154 & 1.0 & 0.0 & 0.68 & 0.91 & 42.60 \\
$22 \mathrm{kV} \mathrm{main}$ & 22 & 0.98 & -2.8 & 2.82 & 0.93 & 41.67 \\
RM TOP, BOT & 22 & 0.98 & -2.8 & 2.87 & 0.7 & 15.72 \\
FM TOP, BOT & 22 & 0.98 & -2.8 & 2.87 & 0.99 & 10.28 \\
ML 3.3 kV & 3.3 & 0.96 & -4.1 & 3.49 & 0.82 & 6.65 \\
2PLR 3.3 kV & 3.3 & 0.96 & -4.3 & 5.91 & 0.82 & 7.74 \\
S/F 3.3 kV & 3.3 & 0.96 & -4.2 & 5.83 & 0.82 & 7.14 \\
\hline
\end{tabular}

Table 9. ESA calculation results for IEEE Std. 519 current report with filter-1.

\begin{tabular}{ccccccc}
\hline \multicolumn{7}{c}{ Harmonic Current Distortion in Percent of Plant Loading } \\
\hline $\begin{array}{c}\text { Harmonic } \\
\text { Number }\end{array}$ & $\mathbf{3 - 1 0}$ & $\mathbf{1 1 - 1 6}$ & $\mathbf{1 7 - 2 2}$ & $\mathbf{2 3 - 3 4}$ & $\mathbf{3 5 - 5 0}$ & ITDD (\%) \\
\hline Odd Harmonics & 3.58 & 0.88 & 1.06 & 0.16 & 0.13 & 4.75 \\
IEEE Limits & 10 & 4.5 & 4 & 1.5 & 0.7 & 12.00 \\
Even Harmonics & 0 & 0 & 0 & 0 & 0 & 0.00 \\
IEEE Limits & 2.5 & 1.13 & 1 & 0.38 & 0.17 & 3.00 \\
Plant Load & & & & & & \\
kVA = 50,000 & & & & & & \\
PCC & & & & & & \\
$\mathrm{I}_{\mathrm{sc}} / \mathrm{I}_{\text {load }}=55.0$ &
\end{tabular}

Table 10. ESA calculation results for IEEE Std. 519 current report with filter-2.

\begin{tabular}{ccc}
\hline \multicolumn{2}{c}{ Harmonic Voltage Distortion in Percent of PCC Base Voltage } \\
\hline & Max Individual & $V_{\text {thd }}(\%)$ \\
\hline PCC Bus & 1.484 & 2.819 \\
IEEE Limits & 3 & 5.00 \\
PCC Base $\mathrm{kV}=22.000$ & & \\
\hline
\end{tabular}




\section{Harmonic Filter Configuration and Measured Power Profile 4.1. Harmonic Filter Configuration}

Figure 5 shows a part of the harmonic filter banks installed in the field. The SR and the capacitor were located at the top, and an unbalanced voltage detector for filter bank protection was located in between them. The 5th and 7th HFs consisted of 6 cans/banks with a single wye 1-parallel connection, and the 11th, 13th, and 22nd HFs consisted of 12 cans/banks with a single wye 2-parallel connection. Figure 6 shows a single line diagram of the 22nd harmonic filter bank. The unbalanced voltage detector had a discharge coil function discharging the residual voltage in the capacitor to less than $50 V_{D C}$ within $5 \mathrm{~s}$ after being disconnected from the system. It also detected the unbalanced voltage between the upper and lower can groups simultaneously when an element failure occurred inside the can [28].

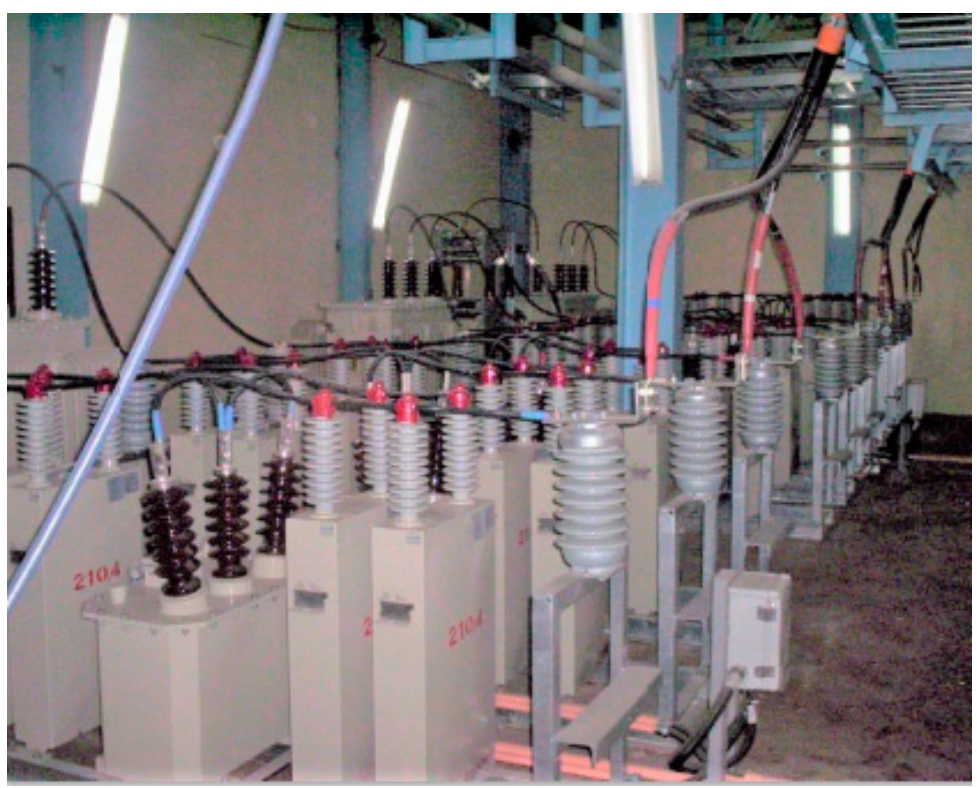

Figure 5. A part of harmonic filter banks.

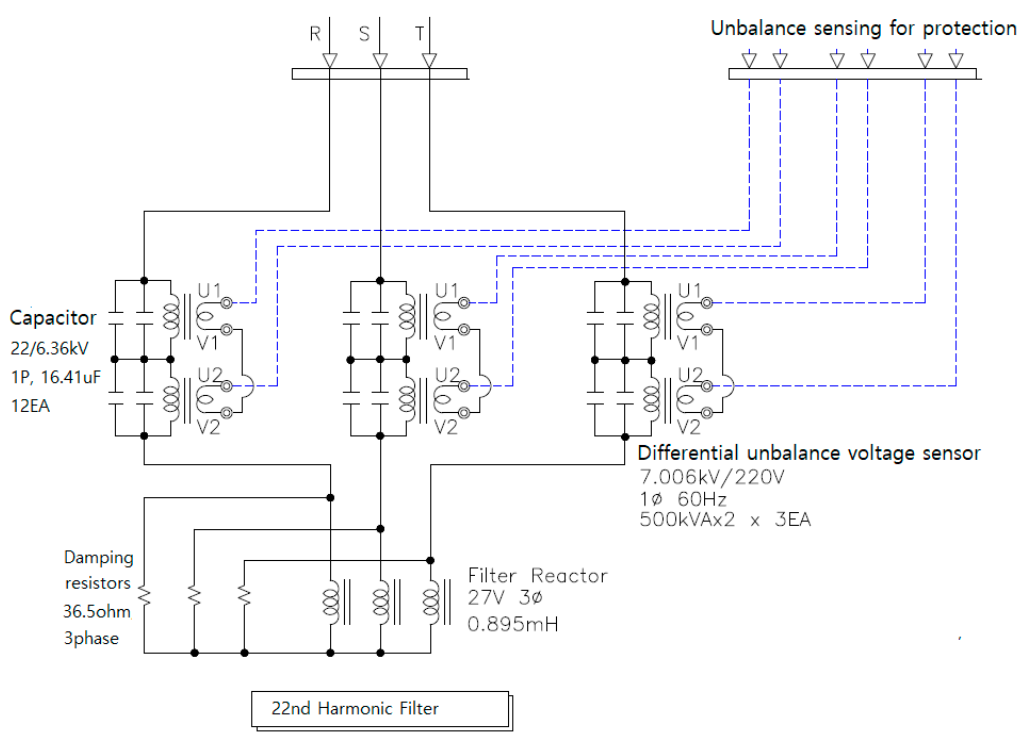

Figure 6. Single line drawing of 22nd HF. 


\subsection{Validation of Results}

\subsubsection{Variations in Power and Voltage}

Figure 7 shows the apparent $(\mathrm{S})$, active $(\mathrm{P})$, and reactive powers $(\mathrm{Q})$ of the plate mill system with and without the filter banks. From 15:53:54, 2nd June, when filter banks were closed, the reactive power was significantly reduced, and it was slightly leading at light loads. Without harmonic filter banks, $S$ and $P$ changed differently. However, it can be seen from Figure 7 that $S$ and $P$ change to approximately the same values as $Q$ decreases when the filter is closed.

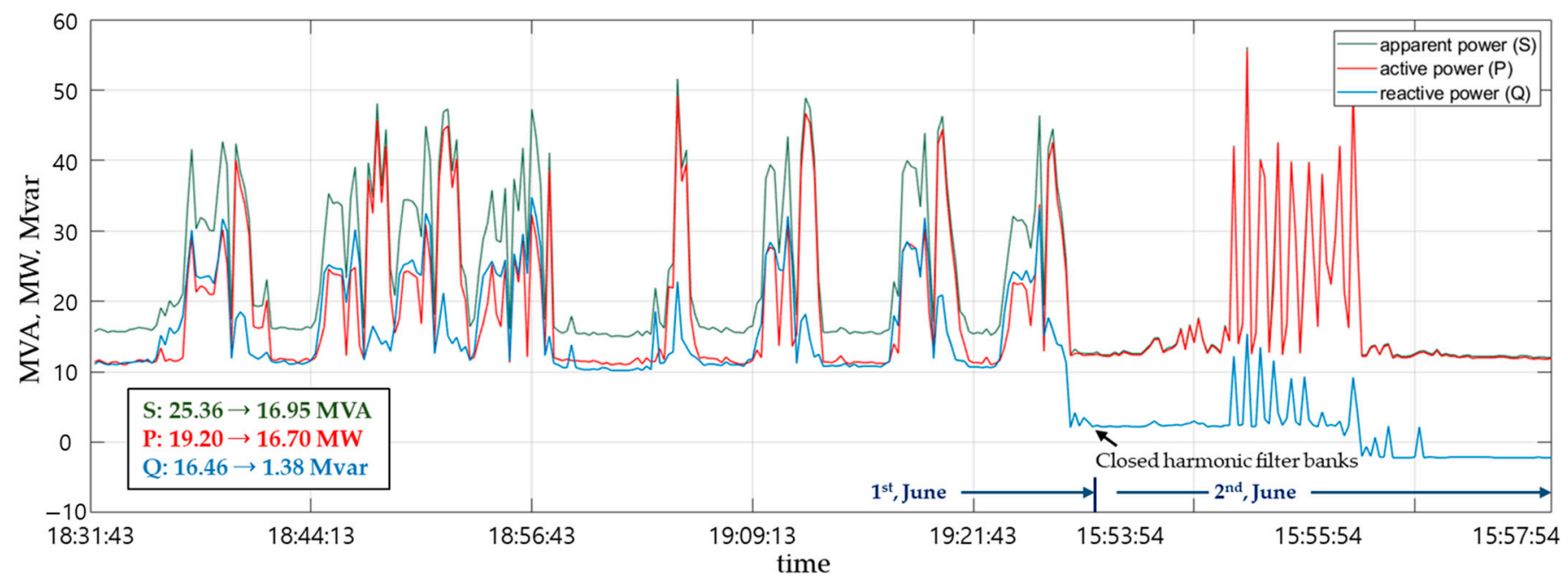

Figure 7. Measured $S, P$, and $Q$ on plate mill system.

Figure 8 shows the maximum line voltage of the $22 \mathrm{kV}$ bus. By comparing the results before and after applying the filter, the range of voltage amplitude improved from 5.3-2.3\% to $3.3-1.5 \%$, variance from 23,434 to $6894 \mathrm{~V}$, and standard deviation from $153.1 \mathrm{~V}$ to $83.0 \mathrm{~V}$ (because of the tap adjustment of the transformer, only the voltage fluctuation depth was considered).

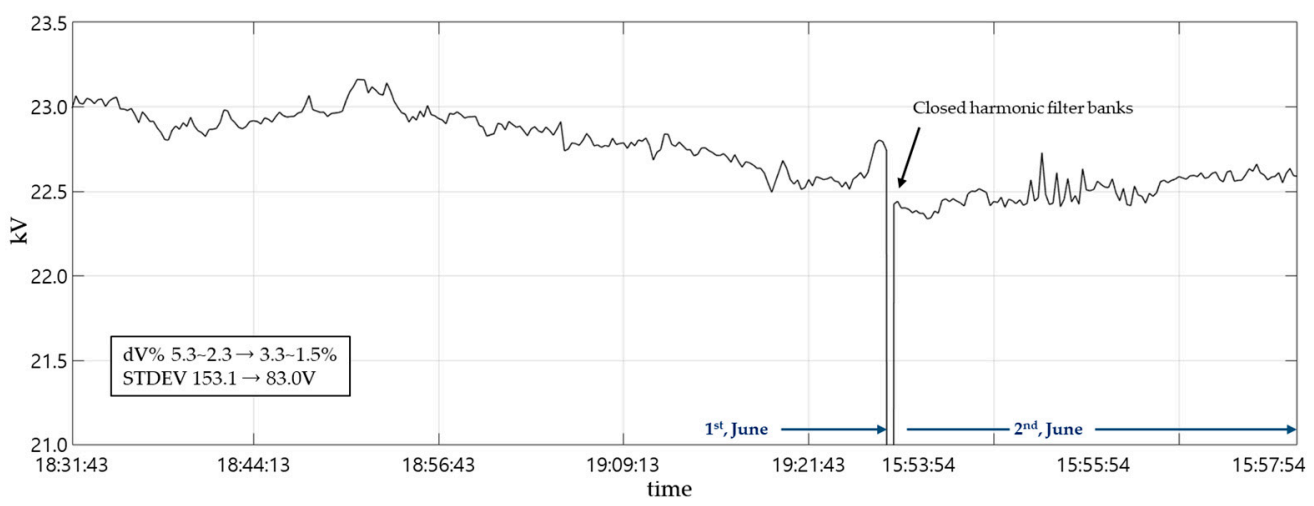

Figure 8. Measured $V_{\max }$ for $22 \mathrm{kV}$ plate mill system.

\subsubsection{Voltage Distortion}

Figure 9 shows the measured values of $V_{\text {thd }}$. The maximum value, average value, and standard deviation improved from 2.60 to $1.05 \%, 1.78$ to $0.70 \%$, and 0.38 to $0.08 \%$, respectively. Contrary to the previous simulation, it showed a significant difference, and the cause of the overall low level was due to the fact that the harmonic generation spectrum data applied during the simulation was based on the worst case scenario. However, it was confirmed that the tendency of the voltage distortion $V_{\text {thd }}$ to improve was similar to the previous simulation. 


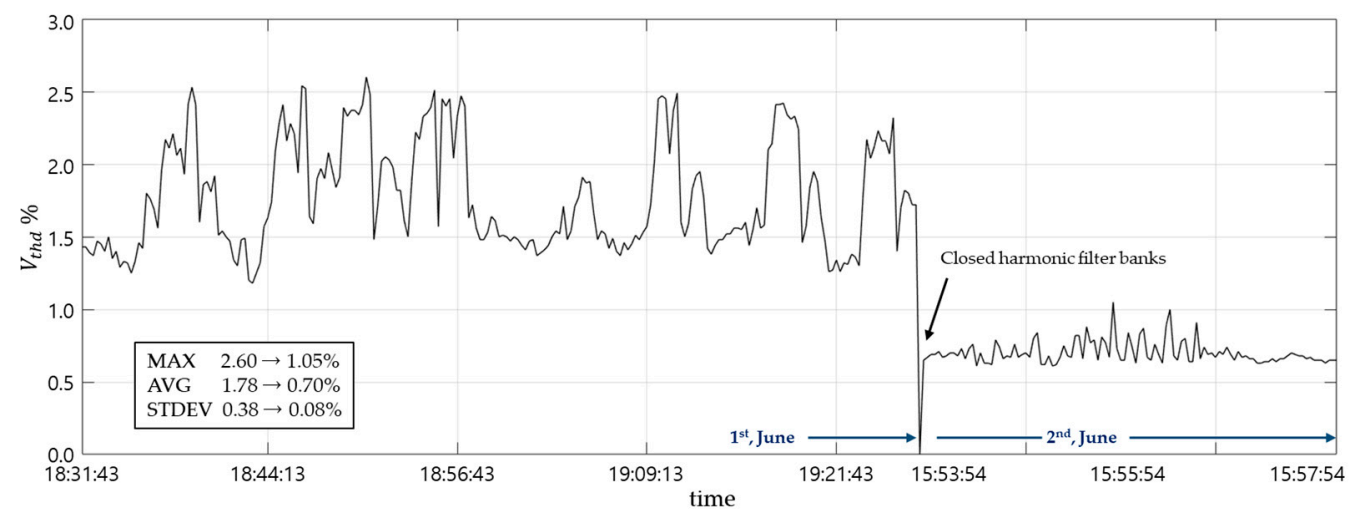

Figure 9. Measured $V_{\text {thd }}$ for $22 \mathrm{kV}$ plate mill system.

4.2.3. Voltage Harmonic Spectrum $V_{5}, V_{7}, V_{11}$, and $V_{13}$

Figure 10 shows the measured harmonic voltage spectra $V_{5}, V_{7}, V_{11}$, and $V_{13}$. Figure 10 shows that for the major harmonic voltage $V_{11}$, the size is significantly reduced from 418 to $73 \mathrm{~V}$. From Figure 10, we can see that $V_{7}$ and $V_{13}$ are decreased from 180 to $94 \mathrm{~V}$ and 169 to $26 \mathrm{~V}$, respectively, but $V_{5}$ is increased from 170 to $194 \mathrm{~V}$. When the tuning frequency of the 5 th $\mathrm{HF}$ was 4.8 th $(288 \mathrm{~Hz})$, the attenuation of the simulation value was $-1.63 \mathrm{~dB}$, but in the actual measurement, $V_{5}$ increased slightly. This is because the curve from the point of the lowest impedance to the peak impedance is steep, as shown by the green curve in Figure 11. To overcome this problem, the two following solutions were proposed. First, it could be improved by changing $Q$. If $Q$ is changed from 80 to 20, as shown in the red in Figure 11, a relatively smooth curve is shown, and the attenuation is improved to $-2.73 \mathrm{~dB}$. The other solution is to move the tuning frequency to the right. If the tuning frequency is considered as 4.9th $(294 \mathrm{~Hz})$, as shown in blue in Figure 11, the attenuation can be improved by $-2.71 \mathrm{~dB}$.

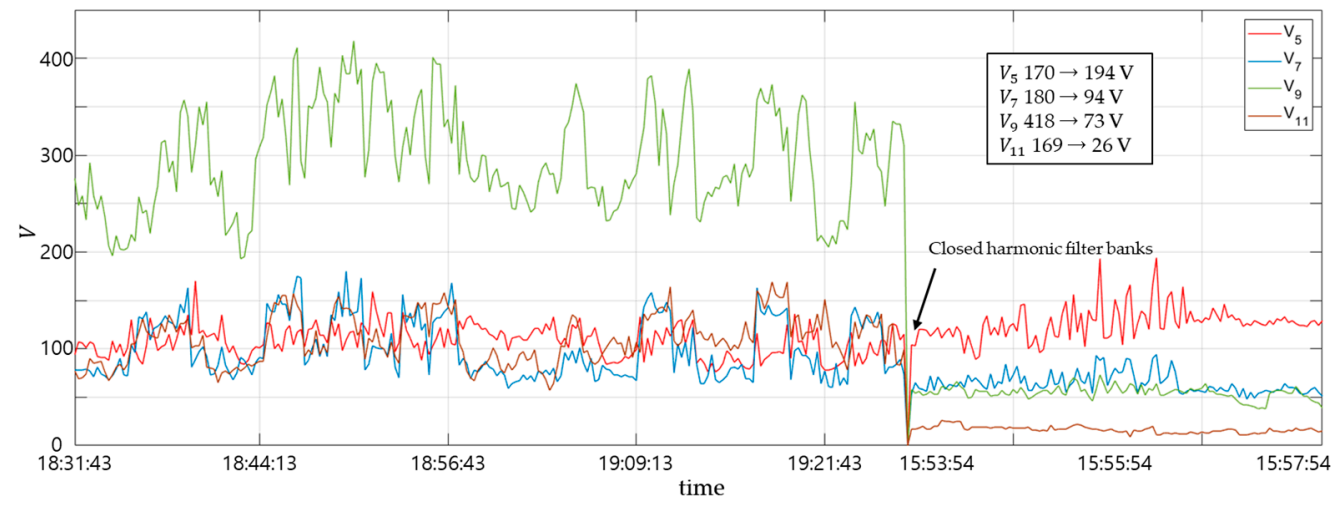

Figure 10. Measured $V_{h(5,7,11,13)}$ for $22 \mathrm{kV}$ system.

\subsubsection{Voltage Harmonic Spectrum $V_{17}, V_{19}, V_{23}$, and $V_{25}$}

Figure 12 shows the measured harmonic voltage spectra $V_{17}, V_{19}, V_{23}$, and $V_{25}$. As shown in Figure 12, the major harmonic voltage $V_{23}$ is improved from 304 to $9 \mathrm{~V}$, and $V_{17}$, $V_{19}$, and $V_{25}$ are decreased from 113 to $26 \mathrm{~V}, 79$ to $15 \mathrm{~V}$, and 255 to $8 \mathrm{~V}$, respectively. 


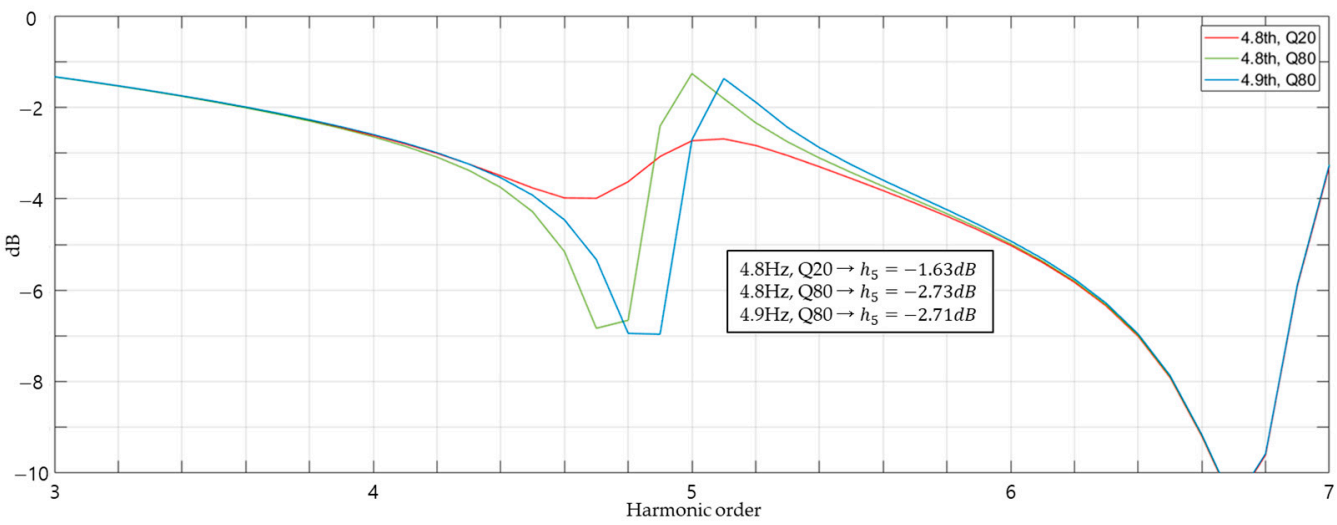

Figure 11. Attenuation with 5th HF parameters changed.

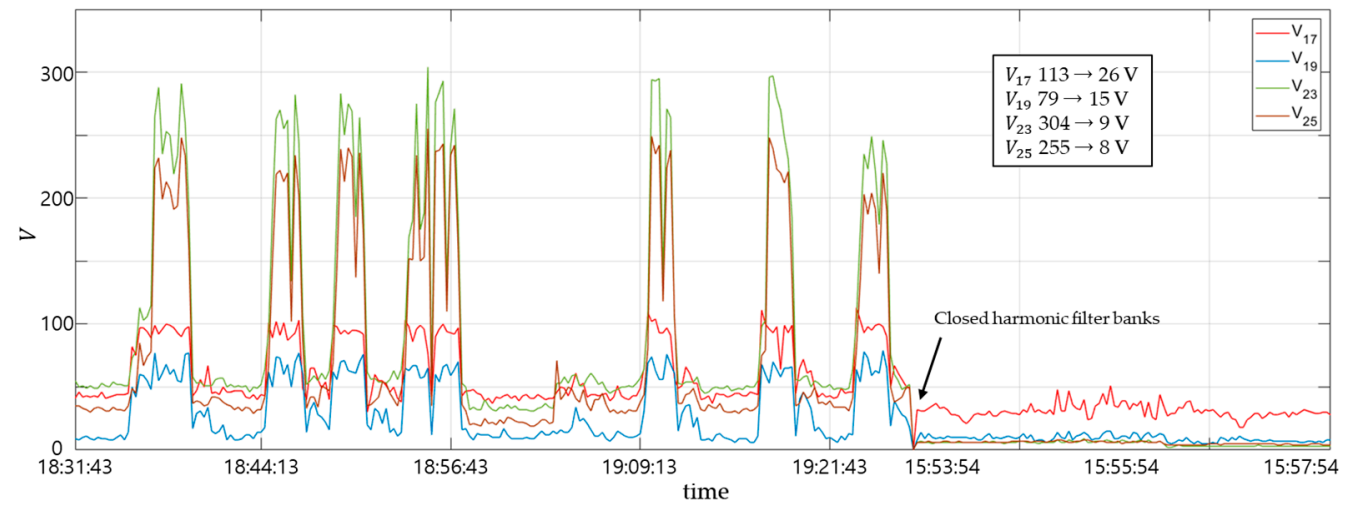

Figure 12. Measured $V_{h(17,19,23,25)}$ on $22 \mathrm{kV}$ system.

4.2.5. Voltage Harmonic Spectrum $V_{29}, V_{31}, V_{35}$, and $V_{37}$

Figure 13 shows the measured harmonic voltage spectra $V_{29}, V_{31}, V_{35}$, and $V_{37}$. As shown in Figure 13, the largest harmonic voltage $V_{37}$ is improved from 164 to $15 \mathrm{~V}$, and $V_{29}, V_{31}$, and $V_{35}$ are decreased from 82 to $5 \mathrm{~V}, 98$ to $5 \mathrm{~V}$, and 119 to $9 \mathrm{~V}$, respectively.

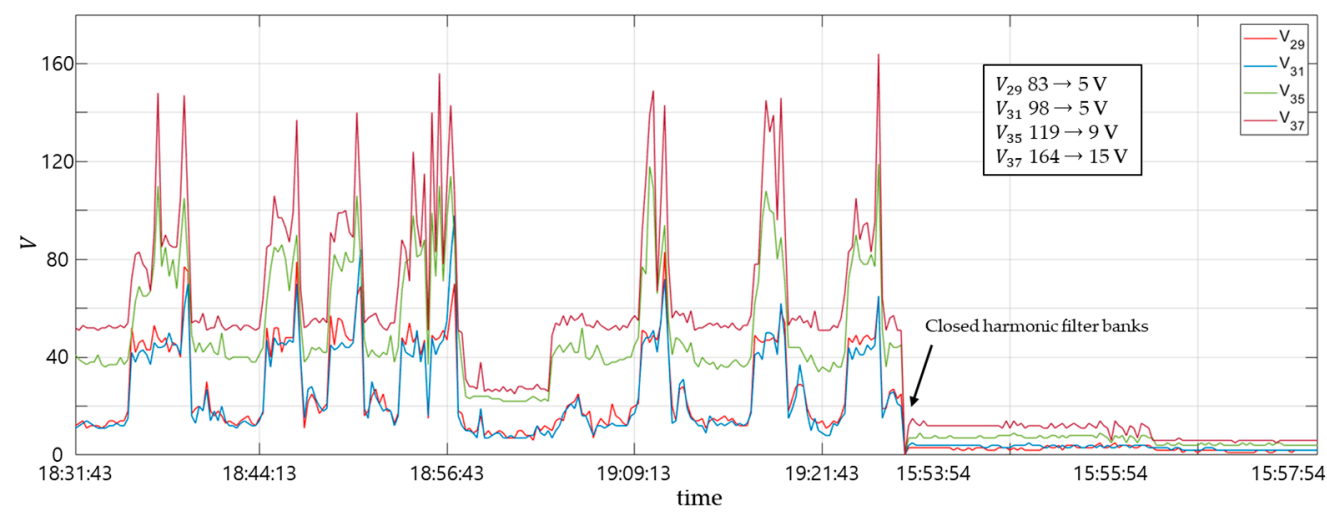

Figure 13. Measured $V_{h(29,31,35,37)}$ on $22 \mathrm{kV}$ system.

4.2.6. Voltage Harmonic Spectrum $V_{41}, V_{43}, V_{47}$, and $V_{49}$

Figure 14 shows the measured harmonic voltage spectra $V_{41}, V_{43}, V_{47}$, and $V_{49}$. As shown in Figure 14, the largest harmonic voltage $V_{49}$ is improved from 160 to $16 \mathrm{~V}$, and $V_{41}, V_{43}$, and $V_{47}$ are decreased from 74 to $9 \mathrm{~V}, 66$ to $8 \mathrm{~V}$, and 138 to $14 \mathrm{~V}$, respectively. 


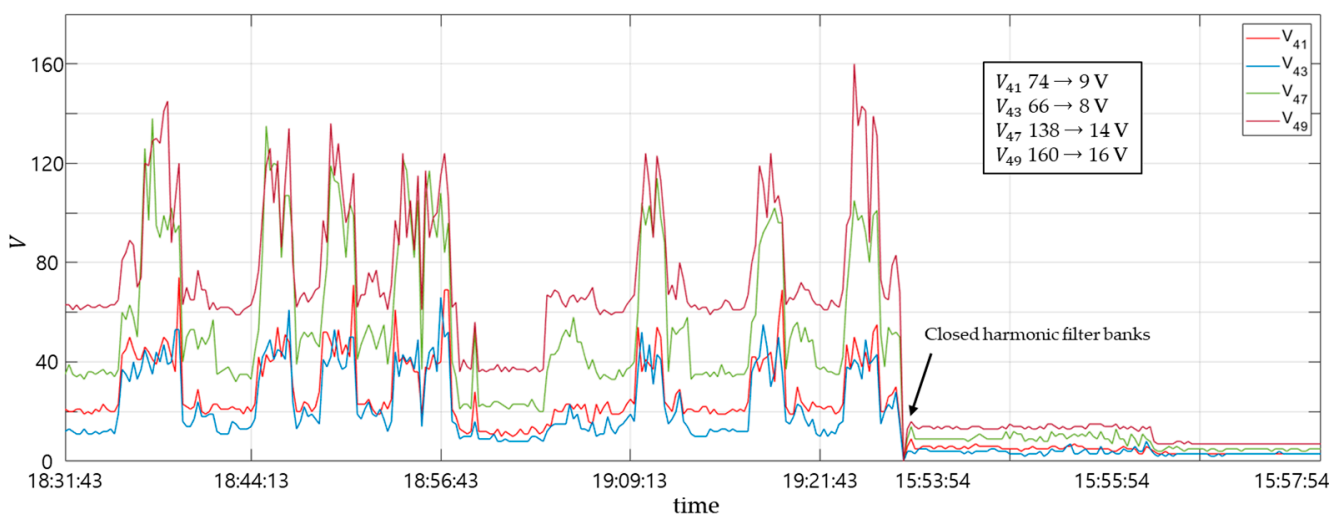

Figure 14. Measured $V_{h(41,43,47,49)}$ on $22 \mathrm{kV}$ system.

\section{Discussion}

It cannot be done without considering the economics of installing filters for harmonic mitigation in the mill power system. The cost of this project was USD 450,000 including switch gears and cubicles, protection relays, capacitors, series reactors, etc. The amount of energy reduction by the filter depends on the loss characteristics of the transformer, showing a difference of $0.4 \%$ before and after application (assume no load loss $0.001 \mathrm{pu}$, load loss $0.008 \mathrm{pu}$ ). The annual energy reduction is calculated as (14) based on the average load (40 MVA). This has the effect of reducing about $84,000 \$$ (US) per year (reflecting Korean electricity bills), and it is estimated that it will take about 5.4 years to recover the investment.

$$
0.4 \% \times 40,000 \mathrm{kVA} \times 24 \mathrm{~h} \times 365 \text { days }=1,401,600 \mathrm{kWh}
$$

It is also possible to consider applying the active power filter to this system. The active power filter does not cause parallel resonance with the system, and real-time compensation of harmonics and reactive power is possible. For this, a 10 MVA step-up transformer with an impedance of about $1 \%$ is required, and it is reasonable to apply the dq transformation control method rather than the FFT control method as it can respond quickly to the load fluctuation characteristics. Except the cost, which is roughly twice that of a passive filter, an active filter is preferred.

\section{Conclusions}

In this study, it was confirmed that a passive harmonic filter system with an optimal capacity in the mill motor drive system could provide an economical solution that compensated for the reactive power and absorbed the harmonics simultaneously. In addition, the following were discussed: (1) harmonic filter bank configuration parameters, (2) key elements of the filter capacitor and SR design, and (3) attenuation of harmonic voltage by current divider $H_{i d}(s)$. To verify the performances of the harmonic filter, voltage fluctuation characteristics and harmonic voltage were also measured.

As a result of the field test, the voltage standard deviation was improved from 153.1 to $83.1 \mathrm{~V}$ with reactive power compensation. Excluding $V_{5}$, a wide range of harmonic voltages such as $V_{7}, V_{11}, V_{13}, V_{17}, V_{19}, V_{23}, V_{25}, V_{29}, V_{31}, V_{35}, V_{37}, V_{41}, V_{43}, V_{47}$, and $V_{49}$, decreased significantly to a satisfactory level. For $V_{5}$, the $Q$ adjustment and tuning frequency of the filter are shown in Figure 11. Finally, this paper is expected to be helpful in the field of harmonic filter applications.

Author Contributions: The main idea was proposed by B.P. and H.Y.; The data and experiment results were collected by B.P. and H.Y.; The simulation results were analyzed by B.P. and J.L.; B.P., J.L. and G.J. wrote the paper. All authors have read and agreed to the published version of the manuscript.

Funding: This research received no external funding. 
Institutional Review Board Statement: Not applicable.

Informed Consent Statement: Not applicable.

Data Availability Statement: Not applicable.

Acknowledgments: This research was supported by the Basic Research Program through the National Research Foundation of Korea (NRF) funded by the MSIT (No. 2020R1A4A1019405).

Conflicts of Interest: The authors declare no conflict of interest.

\section{References}

1. Mjorning, L. ABB Drives and Control System for Hot Flat Rolling Mills Improves Yield and Quality; South East Asia iron and Steel Institute (SEAISI): Shah Alam, Malaysia, 2005.

2. Hosoda, H.; Kodama, S.; Tessendorf, R. Large PWM Inverters for Rolling Mills. Iron Steel Technol. 2008, 5, 65-73.

3. Emadi, A.; Nasiri, A.; Bekiarov, S.B. Uninterruptable Power Supplies and Active Filters; Illinois Institute of Technology: Chicago, IL, USA; CRC Press: Washington, DC, USA, 2005.

4. Yazdani-Asrami, M.; Sadati, S.M.B.; Samadaei, E. Harmonic study for MDF industries: A case study. In Proceedings of the 2011 IEEE Applied Power Electronics Colloquium (IAPEC), Johor Bahru, Malaysia, 18-19 April 2011; pp. 149-154.

5. Arrillaga, J.; Watson, N.R. Power System Harmonics, 2nd ed.; John Wiley \& Sons: Hoboken, NJ, USA, 2003.

6. Yazdani-Asrami, M.; Song, W.; Zhang, M.; Yuan, W.; Pei, X. AC Transport Loss in Superconductors Carrying Harmonic Current with Different Phase Angles for Large-Scale Power Components. IEEE Trans. Appl. Supercond. 2021, 31, 1-5. [CrossRef]

7. Yazdani-Asrami, M.; Mirzaie, M.; Akmal, A.A.S. No-load loss calculation of distribution transformers supplied by nonsinusoidal voltage using three-dimensional finite element analysis. Energy 2013, 50, 205-219. [CrossRef]

8. Yazdani-Asrami, M.; Gholamian, S.A.; Mirimani, S.M.; Adabi, J. Influence of field-dependent critical current on harmonic AC loss analysis in HTS coils for superconducting transformers supplying non-linear loads. Cryogenics 2021, 113, 103234. [CrossRef]

9. Napoles, J.; Leon, J.I.; Portillo, R.; Franquelo, L.G.; Aguirre, M.A. Selective harmonic mitigation technique for high-power converters. IEEE Trans. Ind. Electron. 2009, 57, 2315-2323. [CrossRef]

10. Pogaku, N.; Green, T.C. Harmonic mitigation throughout a distribution system: A distributed-generator-based solution. IEE Proc. Gener. Transm. Distrib. 2006, 153, 350-358. [CrossRef]

11. Sekar, T.C.; Rabi, B.J. A review and study of harmonic mitigation techniques. In Proceedings of the 2012 International Conference on Emerging Trends in Electrical Engineering and Energy Management (ICETEEEM), Tamil Nadu, India, 3-15 December 2012; pp. 93-97.

12. Badrzadeh, B.; Gupta, M. Practical experiences and mitigation methods of harmonics in wind power plants. IEEE Trans. Ind. Appl. 2013, 49, 2279-2289. [CrossRef]

13. Tischer, H.; Pfeifer, T. Hybrid filter for dynamic harmonics filtering and reduction of commutation notches-a case study. In Proceedings of the 2016 17th International Conference on Harmonics and Quality of Power (ICHQP), Belo Horizonte, Brazil, 16-19 October 2016; pp. 261-265.

14. Kihwele, S. Modelling of Shunt Active Power Filter for Harmonics Case Study of Steel Industry. In Proceedings of the 2019 International Conference on Electronics, Information, and Communication (ICEIC), Auckland, New Zealand, 22-25 January 2019; pp. 1-2.

15. de Miranda, G.C.; Primo, H.F.; Calenzani, H.T.; Camargos, I.A. Harmonic mitigation techniques applied to industrial power systems: Real case study with measurements. In Proceedings of the 2018 Simposio Brasileiro de Sistemas Eletricos (SBSE), Niteroi, Brazil, 12-16 May 2018; pp. 1-6.

16. Gonzalez, D.A.; McCall, J.C. Design of filters to reduce harmonic distortion in industrial power systems. IEEE Trans. Ind. Appl. 1987, 3, 504-511. [CrossRef]

17. Ludbrook, A. Harmonic filters for notch reduction. IEEE Trans. Ind. Appl. 1988, 24,947-954. [CrossRef]

18. Phipps, J.K. A transfer function approach to harmonic filter design. IEEE Ind. Appl. Mag. 1997, 3, 68-82. [CrossRef]

19. Das, J.C. Passive filters-potentialities and limitations. IEEE Trans. Ind. Appl. 2004, 40, 232-241. [CrossRef]

20. Jain, S.K.; Agrawal, P.; Gupta, H.O. Fuzzy logic controlled shunt active power filter for power quality improvement. IEE Proc. Electr. Power Appl. 2002, 149, 317-328. [CrossRef]

21. IEEE Standards Association. IEEE Std 519-2014. Recommended Practice and Requirements for Harmonic Control in Electric Power Systems; IEEE Power and Energy Society: New York, NY, USA, 2014.

22. Pérez-Donsión, M.; Pereira, S.J.; Oliveira, F.T. Harmonics and Flicker in an Iron and Steel Industry with AC arc furnaces. In Proceedings of the International Conference on Renewable Energies and Power Quality, Tenerife, Spain, 10-12 April 2019.

23. Harmonic Working Group (IEEE PES T\&D Committee). Guide for Applying Harmonic Limits on Power Systems, P519A/D6; IEEE: Piscataway, NJ, USA, 1999.

24. Aye, T.M.; Naing, S. Analysis of Harmonic Reduction by Using Passive Harmonic Filters. IJSETR 2014, 3, 9142-9147.

25. Kapoor, S.R.; Lalwani, M.K.; Tiwari, S. Harmonic Analysis and Reduction of Separately Excited DC Motor. In Proceedings of the 4th International Conference Advance Trend in Engineering, Technology and Research (ICATETR-2015), Kota, India, 19-20 June 2015; pp. 179-185. 
26. Almutairi, M.S.; Hadjiloucas, S. Harmonics Mitigation Based on the Minimization of Nonlinearity Current in a Power System. Designs 2019, 3, 29. [CrossRef]

27. IEEE Std 1531-2003. IEEE Guide for Application and Specification of Harmonic Filters; IEEE: Piscataway, NJ, USA, 2003 ; pp. 1-66.

28. IEEE Std C37.99-2000. IEEE Guide for the Protection of Shunt Capacitor Banks; IEEE: Piscataway, NJ, USA, $2000 ;$ pp. 1-108.

29. IEEE Std C57.110 ${ }^{\mathrm{TM}}$-2018. IEEE Recommended Practice for Establishing Liquid-Immersed and Dry-Type Power and Distribution Transformer Capability when Supplying Nonsinusoidal Load Currents; IEEE: Piscataway, NJ, USA, 2018; pp. 1-68.

30. Tao, S.; Xiao, X.N. Comparing transformer derating computed using the harmonic loss factor FHL and K-factor. In Proceedings of the 2008 Third International Conference on Electric Utility Deregulation and Restructuring and Power Technologies, Nanjing, China, 6-9 April 2008; pp. 1631-1634.

31. Meng, J.; Jiang, L.; Wang, Y. Study on the Influence of Harmonics on Load Loss of Transformer. In IOP Conference Series: Earth and Environmental Science, Proceedings of the 2020 International Conference on Green Energy, Environment and Sustainable Development, Wuhan, China, 24-25 April 2020; IOP Publishing: Bristol, UK, 2020; p. 012126.

32. IEEE Std 3002.8-2018. IEEE Recommended Practice for Conducting Harmonic Studies and Analysis of Industrial and Commercial Power Systems; IEEE: Piscataway, NJ, USA, 2018; pp. 1-79.

33. Orcajo, G.A.; Rodriguez, D.J.; Ardura, G.P.; Cano, J.M.; Norniella, J.G.; Llera, T.R.; Cifrian, R.D. Dynamic Estimation of Electrical Demand in Hot Rolling Mills. IEEE Trans. Ind. Appl. 2016, 52, 2714-2723. [CrossRef] 